\title{
Content of Vignettes and Ethical Decision Making among Business Education Students at the University of Nairobi, Kenya
}

\author{
Prisca Mary Oluoch \\ Kenya School of Government \\ Email: prisca.oluoch@ksg.ac.ke or priolouch@gmail.com \\ P. O. Box 339-606, Nairobi, Kenya \\ Paul Amollo Odundo \\ Department of Educational Communication and Technology \\ University of Nairobi, Kenya \\ E-mail: odundopaul@yahoo.com \\ P. O. Box 30197 - 00100, GPO, Nairobi, Kenya \\ John Mwangi \\ Department of Educational Communication and Technology \\ University of Nairobi, Kenya \\ E-mail: jmkamau58@gmail.com \\ P. O. Box 30197 - 00100, GPO, Nairobi, Kenya
}

\begin{abstract}
Vignette-based methodologies are frequently used to examine judgments, decision-making processes and ethical sensitivity of business education teachers and learners during the learning process in business ethics instruction. In this study, sources of knowledge content in construction of vignettes, was considered as a foundation on which ethical sensitivity can be inculcated through experiential learning. The study was focused at establishing the effect of vignettes derived from various content sources on ethical decision-making among business education students. A sample of 57 students from a target population provided information through filling questionnaires, which was then analyzed using descriptive statistics. The study adopted Moral Foundations theory (MFT), a social psychological model intended to explain the origins of and variation in human moral reasoning. The finding of the study indicated that vignettes derived from case studies (94.1\%) influence ethical decision-making; interviews (75.4\%) stories (66.7\%), textbooks $(80.7 \%)$ and personal experiences (91.2\%). The study recommended that universities and institutions training teachers should consider developing and adopting vignettes particularly from the learners' personal experiences as an instructional approach in teaching
\end{abstract}


business ethics; business education teachers could adopt vignettes from case studies, textbooks, stories or interviews with business people in business education methods and other subject areas. On practice, the study recommended vignettes as an instructional tool to enhance dialogue, exchange of ideas and critical thinking; and more studies on the extent to which business education teachers have adopted vignettes as an instructional method.

Keywords: Business Ethics; Ethical Decision-Making; Experiential Learning; Vignette Content.

\section{Introduction}

Knowledge content for teaching business ethics at university level is quite broad ranging from stories, historical events and textbooks to research papers. According to Hughes and Huby (2002) knowledge from various sources can be presented to learners studying business ethics in form of vignettes. Using vignettes, knowledge is presented as cases or scenarios, which provide useful focus in teaching business ethics among undergraduate education students. Agreeing with this argument Oluoch and Odundo (2018) asserted that vignettes derived from different content sources can provide stimulus for addressing difficult-to-explore and sensitive issues with individuals and groups in reflecting real life business situations. Extending the argument further, Sims and Sauser (2011) writing on experiences in teaching business ethics, appreciated usefulness of vignette cases in shaping ethical sensitivity in decision-making. As instructional resources various contents of vignettes can be used by business education teachers to encourage a culture of integrity and creativity among learners at university level. In this study the concern was how vignettes derived from case studies, interviews, stories, text books or personal experiences could enable learners to critique a situation, explain a point of view, recall an experience and solve business ethics conundrum.

\section{Case Studies and Ethical Decision Making}

Successful teaching business of ethics requires the teacher to make the study relevant for learners. As noted by Oluoch, Odundo, Mwangi and Oyier (2018) making business ethics more relevant requires adoption of an experiential framework. Vignettes provide an experiential learning framework, which is enjoyable during the learning process, by portraying a business environment that involves a potential ethical dilemma. According to Kelter and Pope (2011) one way of portraying a potential ethical dilemma within a business environment is use of case studies. Supporting this position an article of American Psychological Association (2010) describes case studies as an illustration of a business dilemma with an indicative means of solution or shedding light on the needed investigation to solve ethical issues. Case studies as written descriptions of incidents offer a level of depth, detail and complexity. According to Harland (2014), case studies provide learners with empirical evidence in a contextually unique way by addressing a problem of interest within business professional practice. As an experiential learning tool vignettes derived from case studies provide learners with rich, in-depth knowledge and skills of ethical decision-making that would inculcate ethical sensitivity. 
Further, Miller, Shoptaugh and Wooldridge (2011) added that involvement of learners in experiential learning through vignettes derived from case studies provides the learners and opportunity to be more actively involved in the learning process, which leads to better retention of information for a longer period. This study investigated the effects of vignettes hived off from case studies in shaping learners' ethical sensitivity in making decisions within a business environment.

\section{Interviews and Ethical Decision Making}

Using vignettes as experiential learning platform provides a comprehensive approach in teaching business ethics at university level of education. These sentiments echo Oluoch et al (2018) assertion that vignettes encapsulations allow teachers and learners consider business dilemmas or scenarios in their entirety. In adopting experiential learning approaches in business ethics instruction, teachers and learners could use vignettes from interviews to dissect complex dilemmas and scenarios into isolated ethical issues. Interviews according to Harland (2014) help in facilitating analysis and discussion stepwise towards creating ethical responses in business decision-making. Adoption of interviews in teaching business ethics has the advantage of providing consequences for the decision making through simulations for learners to develop ethical sensitivity. Pan and Sparks (2011) in a study reviewing behavioral ethics noted that emerging literature conceptualizes that ethical decision making can be learnt through learners interviewing practitioners on business dilemmas or scenarios. Through interviews, a measure of ethical sensitivity is developed and tested in a decision-making exercise. Further, Oluoch and Odundo (2018) asserted that vignettes are useful for sensitive areas of inquiry like ethical dilemmas. This study acknowledges that content delivery may help in internalizing the ethical attitude among future business practitioners through interviews in learning business ethics.

\section{Vignettes Stories and Ethical Decision Making}

In experiential learning, stories are used fundamentally to interpret business experiences as noted by Massoudi (2010). Ideally, stories can be sourced from multiple business perspectives and intentionally connecting principles to the concepts required in learning business ethics. Supporting this position Barczyk, Casimer and Doris (2012) asserted that stories naturally expose learners to simulating and connecting events thereby providing meaning into business experiences. As vignettes, stories enable teachers to capture the attention of learners through nurturing a more social atmosphere within class. Agreeing further, Pan and Sparks (2012) argued that vignettes from stories or stories presented in the form of vignettes engage learners' emotions and cognitive abilities during business ethics instructional process. In teaching business ethics, stories in various formats are used as powerful and successful support for learners to develop ethical sensitivity. As noted by Mohd Ghazali (2011) stories in the form of vignettes enable learners to encounter practical ethical dilemmas and complex business situations like occurrences in real business environments. Discussions accompanying stories shape learners' personal perceptions such as beliefs, attitudes, behavior, values and knowledge. In concurrence Shafer, Poon and Tjosvold (2013) argued that personal perceptions developed through stories 
influence ethical sensitivity among business education learners. As a learning achievement, ethical sensitivity among business education learners would encourage a culture of integrity and creativity. This study sought to establish the effectiveness of vignette stories in ethical decision-making among University of Nairobi business education learners.

\section{Text Book Extracts and Ethical Decision making}

Textbooks serve as a guide for business ethics learners, by providing a general outline of the concepts of intended content. Qualters (2010) writing on experiential learning methodologies noted that from textbooks vignettes can be extracted to relay information piecemeal, unit by unit in an orderly way to aid learners in processing of the information. Textbooks therefore may provide unit information for instructing learners on ethical principles and moral reasoning skills. This according to Massoudi (2010) reinforces learners' desires to be ethically sensitive. Textbooks usually present a relatively straightforward approach to encouraging business learners to develop an ethical ideology to articulate core personal values. As noted by Badua, Sharifi and Mediavilla (2014) extraction of vignettes from textbooks provides a learner-centered approach in teaching business ethics that assists thought process and decision-making. Compared to traditional lectures, experiential learning using vignettes derived from textbooks enables learners gain knowledge in business ethical issues, which could be applied in a real-life situation. In this study the focus is how vignettes from textbooks would influence ethical decision-making among business ethics learners through emphasis, diversity, and integration and sequential presentation of concepts and material in aiding learning.

\section{Personal Experiences and Ethical Decision making}

In experiential learning every individual brings to each situation personal knowledge and experiences about a particular phenomenon. Davis, DeZoort and Kopp (2006) asserted that personal experiences plus their accompanying discussion questions enhances moral perception among learners in as far as decision-making is concerned. This would then contribute towards personal perceptions while at the same time contributing to another individual's need to learn. As noted by Dagar and Yadav (2016) teaching business ethics requires cognition and is most effective when devised by learners themselves. Personal experiences packaged as vignettes would elicit learners' ethical reasoning process resulting in articulation of varied ideas. Further, Ismail and Mohd Ghazali (2011) suggested that ideas from peers brings into focus a comparative approach in experiential learning. Ethical content derived from learners and integrated in training modules would enhance effectiveness in teaching business ethics. To this end Dagar and Yadav (2016) asserted that by using vignettes developed from personal experience, learners form a grounded basis for class discussion on ethical-decision making. Therefore, this study sought to establish effectiveness of personal experiences in teaching business ethics among university students.

\section{Statement of the Problem}

Knowledge from various sources can be presented to learners studying business ethics in form of vignettes. Whichever the source such knowledge should 
provide useful focus in teaching business ethics among undergraduate education students. Empirically, it had been established that vignettes as experiential learning tools have influence on shaping ethical sensitivity among learners in various fields of study. Equally, vignettes have been used to shape ethical ideology among business education learners with minimal emphasis of source of knowledge. However, there was a need to establish the extent to which various knowledge content for vignette would influence decision-making through inculcating ethical sensitivity among learners studying to be teachers of business education. This study, focused on establishing how case studies, interviews, stories, textbooks and personal experience as knowledge sources for vignettes would influence decision-making among university learners training to teach business education in secondary schools in Kenya.

\section{Purpose of the Study}

The purpose of this study was to investigate the effects of content of vignettes on ethical decision-making among business education students at the University of Nairobi, Kenya

\section{Theoretical Framework}

Moral foundations theory (MFT) is a social psychological model intended to explain the origins of and variation in human moral reasoning based on innate, modular foundations. Proposed by Jonathan Haidt and Jesse Graham who came up with five foundations from which moral psychology have been developed by a diverse group of collaborators (Koleva, Graham, Iyer, Ditto \&Haidt, 2012). In this study, sources of knowledge content in construction of vignettes was considered a moral psychology foundation on which ethical sensitivity can be inculcated through experiential learning. As noted by Koleva et al (2012), moral psychology intersects moral judgment, attitudes, and emotion. Ethical sensitivity is an ideological variable that can be enhanced through experiential learning to enable one to develop moral judgment, attitudes, and emotion. Although in formative stages of developing MFT focused on cultural norms, morality and subsequently on political ideology, this study took a turn towards ethical issues. Ideally, ethical ideology as noted by Oluoch et al (2018) can be shaped through experiential learning involving use of vignettes. Therefore, in adopting moral foundation theory this study was cognizant to the fact that source of knowledge is basis through which ethical sensitivity can be developed among learners. Vignettes derived from which knowledge sources are foundations through ethical sensitivity can be developed through experiential learning.

\section{Conceptual Framework}

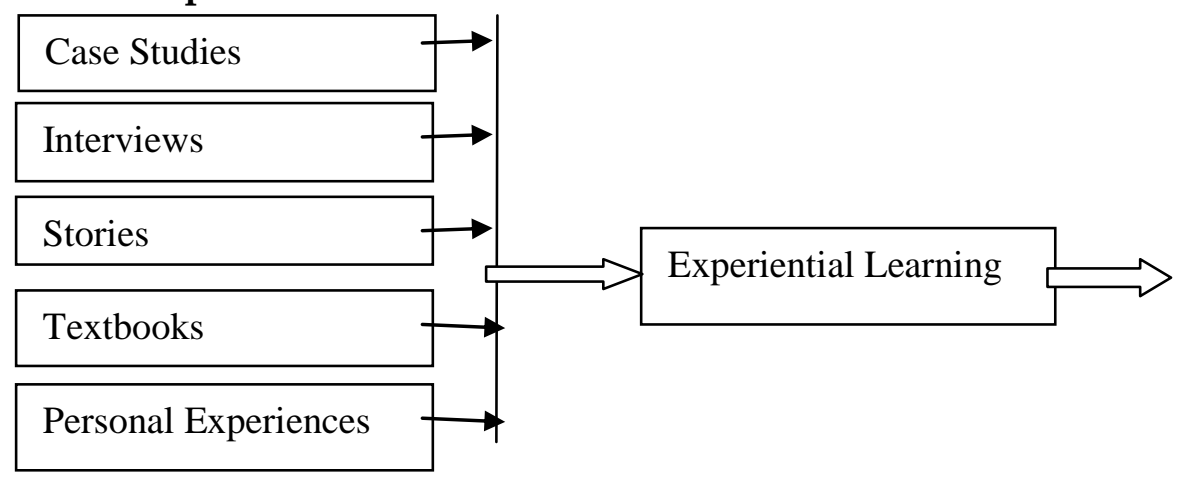

Ethical Decision Making 


\section{Methodological Approach}

Figure 1: Conceptual Framework

This study adopted survey design was to provide information on the effects of content of vignettes on ethical decision-making among business education students through use of questionnaires. Survey design was particularly useful because the population was dispersed areas large geographically, since the study was carried when the students were in teaching practice (Roberts \& Sikes, 2011). The target population of the study was the 134 fourth year business education students undertaking a bachelor course at University of Nairobi. Information was sourced from 57 randomly sampled students from their stations for teaching practice within Nairobi Metropolitan for the survey. Data analysis involved the application of the two types of statistical technique namely descriptive statistics and presented using tables and figures

\section{Findings and Discussions}

Information presented as findings for discussion in this study was sourced from 57 business education students who were on teaching practice within Nairobi Metropolitan.

\section{Demographic Characteristics of Respondents}

First and foremost, findings on demographic characteristics was presented in Table 1.

Table 1: Demographic Information

\begin{tabular}{llcc}
\hline Variable & Indicators & Frequency & Percentage \\
\hline Gender & Male & 34 & 59.6 \\
& Females & 23 & 40.4 \\
Teaching & Mathematics and Business & 38 & 66.7 \\
& $\begin{array}{l}\text { Education } \\
\text { Geography and Business }\end{array}$ & 14 & 24.6 \\
& Education & & \\
& Business Education and & 5 & 8.8 \\
Business & Physical Education & & 57.9 \\
Experience & Yes & 33 & 42.1 \\
\hline
\end{tabular}

Vignettes as experiential learning instructional resources are adopted in teaching ethical issues within business to all individuals irrespective of gender. As indicated in Table 1, male students taking business education at degree level at the University of Nairobi are $59.6 \%$ (34) compared to their female counterparts who are $40.4 \%$ (23). These findings are an indication that females are fairly represented in the business education course at undergraduate level, even though they are fewer than their male colleagues. Secondly, in as much as males were slightly more and given the fact that the sample was randomly obtained, provides a base for fairness and impartiality in discussions to follow on knowledge content of vignettes. On issues to do with teaching subjects apart from business education, students are being trained to teach other subjects as 
depicted in Table 1. These include mathematics, geography and physical education (PE). University of Nairobi requires that Bachelor of Education Students must have two teaching subjects. In Table 1 it is indicated that $66.7 \%$ (38) of business education students are being trained to teach mathematics as second teaching subject, 24.6\% (14) Geography and 8.8\% (5) Physical Education. After establishing that majority of business education students teach mathematics, it was prudent to ascertain gender distribution as far as second teaching subject is concerned. This is presented in Table 2 .

Table 2: Gender of Respondents and Teaching Subject

\begin{tabular}{|l|c|c|c|c|}
\hline & $\begin{array}{c}\text { Mathematics } \\
\text { and Business } \\
\text { Education }\end{array}$ & $\begin{array}{c}\text { Geography and } \\
\text { Business } \\
\text { Education }\end{array}$ & $\begin{array}{c}\text { Business } \\
\text { Education and } \\
\text { Physical Education }\end{array}$ & Total \\
\hline Male & 22 & 8 & 3 & $\mathbf{3 3}$ \\
\hline Female & 16 & 6 & 2 & $\mathbf{2 4}$ \\
\hline Total & $\mathbf{3 8}$ & $\mathbf{1 4}$ & $\mathbf{5}$ & $\mathbf{5 7}$ \\
\hline
\end{tabular}

Findings presented in Table 2 indicate proportional distribution of both genders taking mathematics, geography and physical education as second subjects. This is an indication that gender is not significant in determining choice of second teaching subject. The findings are therefore in concurrence with Stedham and Beekun (2013) who argued that as much as boys are perceived to have a stronger affinity and interest towards mathematics, girls are equally capable of studying and excelling in the subject. Secondly as in the case of mathematics proportional distribution is shown in Table 2 and this is also seen in physical education. Interest in teaching subjects may be varied among Bachelor of Education Students, but as noted by Akinnuoye, Akinnuoye, Wan Shuib and Mokhtar (2015) in a study carried out on school curriculum implementation, policy also has an influence. Secondly as noted by Stedham and Beekun (2013), beyond policy, availability and utilization of instructional resources and related subject activities together with the scope plus pedagogical approach could determine students' choice of second teaching subject. Finally, of the three subjects, physical education is the least preferred and could be attributed to the fact that it's not an examinable subject in Kenya Certificate of Secondary Education (KCSE).

\section{Influence of Vignettes Content on Ethical Decision Making}

Vignettes of various contents can be used as instructional resources in teaching business ethics to encourage a culture of integrity and creativity among learners at university level. In this study results of business education students' perception on the extent to which vignettes derived from case studies, interviews, stories, text books or personal experiences could enable learners to critique a situation, explain a point of view, recall an experience and solve business dilemmas was posted in Table 2 . 
Table 3: Response on Influence of Vignettes Content on Ethical DecisionMaking

\begin{tabular}{lcccccccccc}
\hline & $\begin{array}{l}\text { Case } \\
\text { Studies }\end{array}$ & \multicolumn{2}{c}{ Interviews } & Stories & \multicolumn{2}{c}{$\begin{array}{l}\text { Textbook } \\
\text { Extracts }\end{array}$} & \multicolumn{2}{c}{$\begin{array}{l}\text { Personal } \\
\text { Experiences }\end{array}$} \\
\hline & $\mathrm{N}$ & $\%$ & $\mathrm{n}$ & $\%$ & $\mathrm{n}$ & $\%$ & $\mathrm{~N}$ & $\%$ & $\mathrm{n}$ & $\%$ \\
Agree & 51 & 89.5 & 43 & 75.4 & 38 & 66.7 & 46 & 80.7 & 52 & 91.2 \\
Uncertain & 2 & 3.5 & 6 & 10.5 & 13 & 22.8 & 4 & 7.0 & 1 & 1.8 \\
Disagree & 4 & 7.0 & 8 & 14.0 & 6 & 10.5 & 7 & 12.3 & 4 & 7.0 \\
Total & $\mathbf{5 7}$ & $\mathbf{1 0 0}$ & $\mathbf{5 7}$ & $\mathbf{1 0 0}$ & $\mathbf{5 7}$ & $\mathbf{1 0 0}$ & $\mathbf{5 7}$ & $\mathbf{1 0 0}$ & $\mathbf{5 7}$ & $\mathbf{1 0 0}$ \\
\hline
\end{tabular}

a. Case Studies

From Table 2, it is indicated that $89.5 \%$ (51) business education students agreed that vignettes derived from case studies influence ethical decision-making. This can be attributed to the fact that most case studies originate from real life situations making them believable by learners. Originating from real business experience enables case study vignettes to be effective in influencing ethical decision-making. This is in agreement with Oluoch et al (2018) assertion that vignettes provide experiential platform from which learners' ethical sensitivity could be shaped. Specifically, vignettes derived from case studies sometimes have ethical dilemmas that learners will resonate with. Resonating with ethical dilemmas as noted by Kelter and Pope (2011) is one way through which case studies help leaners to become ethically sensitive within portrayed potential business environment. Table 2 also indicates that 3.5\% (2) of students were uncertain and another $7.0 \%$ (4) disagreed that vignettes originating from case studies influence ethical decision-making. Uncertainty of $2 \%$, could be attributed to the fact that some students could not have had knowledge or experience of vignettes as an instructional resource. This is because exposure to vignettes as noted by Oluoch et al (2018) brings into the classroom relevant business experiences, which help learners develop ethical sensitivity.

For those who disagreed it could be due to the fact the issues are not related to what they have been exposed to and seems irrelevant to them. However, many students agreeing is a confirmation that case studies vignettes provide an experiential learning framework, which is enjoyable by portraying a business environment that involves a potential ethical dilemma. Case studies tend to give detailed information, are more refined and are perceived to be authentic since they are based on real happenings. This is in tandem with Harland (2014) assertion that case studies provide learners with empirical evidence in a contextually unique manner and address problems of interest within business professional practice. As much as vignettes derived from case studies may be more informative, they could be bias in that they also have third party reasoning through analysis where someone has already made up his mind. This could make some students be either uncertain or disagree that vignettes derived from case studies would influence ethical decision-making. This supports a position taken by American Psychological Association (2010) which describe case studies as illustrations of business dilemmas with an indicative means of solution or shedding light on the needed investigation to solve an ethical issue. However, 
vignettes from case studies as written description of incidents offer a level of depth, detail and complexity in a less broad scope. As an experiential learning tool case study vignettes provide learners with rich, in-depth knowledge and skills of ethical decision-making that would inculcate ethical sensitivity (Shoptaugh \& Wooldridge, 2011). In general case studies enable learners to more actively retain information and for a longer period.

\section{b. Interviews}

Results in Table 2 indicate that 75.4\% (43) business education learners agreed that vignettes derived from interviews enhance ethical decision-making. This can be attributed to the fact that interviews are real for those involved. The responses from business education learners confirms Oluoch and Odundo (2018) assertion that vignettes bring a personal touch in experiential learning and in this case, reality comes through persons involved in ethical dilemmas. Using vignettes derived from interviews as experiential platform provides a comprehensive and personal approach in teaching business ethics at university level of education. The fact that $10.5 \%$ (6) were uncertain that interviews derived vignettes do not influence ethical decision masking can be explained by the fact that information is raw compared to case studies. For experiential learning purpose interviews provide learners with an opportunity to think through what the interviewee is saying in respect to decision-making. Thinking through would be difficult for $14.0 \%$ (8) of business education students who are indicated in Table 2 to have disagreed that interviews influence ethical decision-making. However as noted by Oluoch et al (2018) interview vignettes encapsulations allow teachers and learners consider business dilemmas or scenarios in their entirety. In adopting experiential learning in business ethics instructions, teachers and learners could use interviews as vignettes in dissecting complex dilemmas into isolated ethical issues.

The fact that more learners were uncertain and disagreed compared to case studied is because they could be lacking capacity to think beyond the spoken word in order to make an ethical decision. However, according to Harland (2014) vignettes derived from interviews help in facilitating analysis and discussion stepwise towards creating ethical responses in business decisionmaking. As much as interviews can be more abstract than case studies, their adoption in teaching business ethics has the advantage in that it provides consequences for the decision making through simulations for learners to develop ethical sensitivity. Concurring with Pan and Sparks' (2011) findings, conceptualizing interviews and building ethical sensitivity could be difficult to some learners. In supporting the fact that interviews influence ethical decisionmaking Pan and Sparks (2011) asserted that learners need to be ready to analyse information from interviewing practitioners on business dilemmas or scenarios. Ideally, interviews being more real for those involved, experiential learning would be achieved through analysis of actions of persons involved in the dilemma. This would enable learners to develop ethical sensitivity, which forms the basis of decision-making process. Ethical sensitivity as noted by Oluoch and Odundo (2018) is better developed when individual practitioners are interviewed in the form of vignettes through inquiry on business dilemmas. 


\section{c. Stories}

Table 2 indicates that $66.7 \%$ (38) of the interviewed business education learners agreed that vignettes derived from stories enhance ethical decision-making when used as instructional resources. Compared to other sources of vignettes content stories are rated lower and this can be attributed to the fact that they are hypothetical to a very large extent. These results agree with Massoudi (2010) assertion that hypothetical nature of stories is fundamentally important in interpreting business experiences during experiential learning. They can be derived from a broad business perspective and intentionally provide connecting principles to the concepts required in learning business ethics. The fact that results in Table 2 show that up to $22.8 \%$ (13) business learners were uncertain of influence of vignettes derived from stories in enhancing ethical decision-making, is due to the fact they do not accurately depict real life situations. This supports Barczyk, Casimer and Doris (2012) position that stories would expose learners to simulating and connecting events from which they are needed to derive meaning into ethical business decisions. Teacher would therefore need vignette stories to capture learners' attention through nurturing a more social atmosphere within class from which they are expected to develop ethical sensitivity. This as noted by Pan and Sparks (2012) would engage learners emotions and cognitive abilities needed for shaping ethical sensitivity during business ethics instructional process.

As much as stories derived vignettes can relate o business environment dilemmas, being hypothetical may make learners not believe them. Hypothetical nature of stories derived vignettes would require adoption of various formats to successfully help learner develop ethical sensitivity. This is in tandem with Mohd Ghazali (2011) assertion that as much as story vignettes enable learners to encounter practical ethical dilemmas like occurrences in business environment more need to be done for enhancing learners' ethical sensitivity. Discussions accompanying stories shape learners personal perceptions such as beliefs, attitudes, behavior, values and knowledge. The authenticity of stories in shaping ethical sensitivity of learners therefore depends on the pedagogical approach employed in class. As noted by Shafer, Poon and Tjosvold (2013), instructional methods employed would influence development of leaners' personal perceptions of business dilemmas in stories and this in turn would enhance ethical sensitivity among them. Effectiveness of vignettes derived from stories in influencing ethical decision-making depends on how serious learners analyze presented business dilemmas during instructional process. Stories tend to be heavily linked to the instructional style to make them believable in terms of eliciting ethical decision-making from business dilemmas. As a learning achievement, ethical sensitivity developed from stories among business education learners would encourage a culture of integrity and creativity as far as decision-making is concerned.

\section{d. Text books}

Results in Table 2 shows that $80.7 \%$ of business education learners agreed that vignettes derived from text books influence ethical decision-making. This could be attributed to the fact that textbooks contain material that learners are used to, 
and their expectations may be more easily met. This is in concurrence with Qualters (2010) position that in experiential learning textbooks extracted vignettes relay information piecemeal, unit by unit in an orderly way to aid learners in processing of the information. The authority of text books, and the link with what they are expected to know according to the syllabus or course outline for example for exams makes learners take them seriously. However, Table 2 also indicate that 12.3\% (7) business education students disagreed that text book derived vignettes do not influence ethical decision making. This can be attributed to the fact that learners do not perceive information from textbooks as real and instead looking at them as purely academic material. Textbooks serve as a guide to business ethics phenomenon by providing a general outline of the concept of intended content, hence a challenge in using them to develop ethical ideology.

Textbooks provide unit information for instructing learners on ethical principles and moral reasoning skills but lack personal attachment to business dilemmas. This according to Massoudi (2010) could only be helpful in reinforcing learners' desires to be ethically sensitive in making decisions. However, the fact that textbooks present a relatively straightforward approach should be encouraging to business education learners to develop an ethical ideology to articulate core personal values. This agrees with Badua, Sharifi and Mediavilla (2014) position that extraction of vignettes from textbooks provides a learner-centered approach in teaching business ethics that assists thought process and decision-making. Compared to traditional lectures, experiential learning using vignettes derived from textbooks enables learner gain knowledge on business ethical issues, which could be applied in a real-life situation. Irrespective of being abstract textbooks would influence ethical decision-making among business ethics learners through emphasis, diversity, integration and sequential processes in aiding learning.

\section{e. Personal experiences}

Results in Table 3 indicates that 91.2\% (52) business education learners agreed that personal experiences influence ethical decision-making. This is the highest and seems to suggest that the more real and authentic source of content in using vignettes greatly contributes to shaping ethical sensitivity among business education learners. It means individuals bring personal knowledge and experiences in a situation about a particular phenomenon during experiential learning in class. The study findings are in concurrence with Davis, DeZoort and Kopp (2006) assertion that personal experiences plus accompanying discussion questions enhance moral perception among learners in as far as decision-making is concerned. Personal experience creates a psychological attachment, which brings business situation dilemmas closer to learners. It may not matter whether they are experiences from learners, teachers or a third party. Personal experiences contribute towards development of ethical sensitivity during experiential learning. Contribution of personal experiences in influencing ethical decision-making. 
While personal experiences are contributing to other individuals' need in learning Dagar and Yadav (2016) noted that teaching business ethics required cognition is most effective when devised by learners themselves. The findings of this study confirm that personal experiences packaged as vignettes would elicit learners' ethical reasoning process resulting in articulation of ideas. Further, the findings are in agreement with Ismail and Mohd Ghazali (2011) suggestion that ideas from peers brings into focus a comparative approach in experiential learning. With less than $10 \%$ of business education learners either being uncertain or disagreeing, it is a confirmation that ethical content derived from learners and integrated in training modules would enhance effectiveness in teaching business ethics. Finally, it is worth noting that the study findings agree with Dagar and Yadav (2016) assertion that by using vignettes developed from personal experience form a grounded basis for class discussion on ethicaldecision making. In conclusion the stud has established effectiveness of personal experiences in teaching business ethics among university students in shaping ethical decision-making

\section{Conclusion}

Case studies are the most common source of vignettes. Case studies tend to be long and with a focus on multiple themes. Conversion of cases into vignettes make them appropriate, short and focused for teaching undergraduates business ethics. In form of vignettes case studies bring business reality to class. In most cases they originate from real life studies making them believable by learners and effective in influencing ethical decision-making. Vignettes from case studies therefore provide experiential platform from which learners' ethical sensitivity is shaped. Ideally, vignettes derived from case studies have business environment ethical dilemmas that learners will resonate with and help leaners to become ethically sensitive. Case studies vignettes tend to give more detailed information more refined and are perceived to be authentic since they are based on real happenings. This provides learners with empirical evidence in a contextually unique way when addressing a problem of interest within business professional practice. However, as much as vignettes derived from case studies may be more informative, they could be biased in that they also have third party reasoning through analysis where someone has already made up his mind. This could make some students be either uncertain or disagree that vignettes derived from case studies would influence ethical decision-making especially where the ideas presented in the case are divergent from the learners' ideas. In conclusion vignettes from case studies as written descriptions of incidents offer a level of depth, detail and complexity in a less broad scope.

Interviews can be more abstract than case studies and are significantly real to those involved. However, interview vignettes bring a personal touch in experiential learning and making reality to come through persons involved in ethical dilemmas. Using vignettes derived from interviews as experiential platform provides a comprehensive and personal approach in teaching business ethics at university level of education. For experiential learning purpose interviews provide learners with an opportunity to think through what the interviewee is saying in respect to decision-making. Encapsulations of interview vignettes allow teachers and learners consider business dilemmas or scenarios in 
their entirety. Therefore, in adopting experiential learning in business ethics instruction, teachers and learners could use interviews as vignettes in dissecting complex dilemmas into isolated ethical issues. The fact that more learners were uncertain and disagree compared to case studied is because they could be lacking capacity or the habit to think critically beyond the spoken word in order to make an ethical decision. However, it is worth noting that vignettes derived from interviews help in facilitating analysis, critical thinking and discussion stepwise towards creating ethical sensitivity, which is key in business decisionmaking. Finally, in as much as interviews can be more abstract than case studies, their adoption in teaching business ethics has the advantage in that it provides consequences for the decision-making through simulations for learners to develop ethical sensitivity.

Story lines are important for eliciting conversations and consideration of alternatives among learners. This would foster critical thinking and reflection in learning business ethics at undergraduate level. Though hypothetical, stories are fundamentally important in interpretation of business experiences during experiential learning. They can be derived from a broad business perspective and intentionally connecting principles to the concepts required in learning business ethics. In experiential learning vignettes derived stories would expose learners to simulating and connecting events to derive meaning into ethical business decisions. Teachers need oral or written stories as vignettes to capture learners' attention through nurturing a more social atmosphere within the class from where they are expected to develop ethical sensitivity. This results in engaging learners' emotions and cognitive abilities needed for shaping ethical sensitivity during business ethics instructional process. Finally, hypothetical nature of stories derived vignettes requires adoption of various formats to successfully help learner develop ethical sensitivity. In this way story vignettes would enable learners to encounter practical ethical dilemmas similar to occurrences in business environments. More needs to be done for enhancing learners' ethical sensitivity through stories. Discussions accompanying stories shape learners personal perceptions such as beliefs, attitudes, behavior, values and knowledge. Stories authenticity in shaping ethical sensitivity of learners therefore depends on the pedagogical approach employed. Stories tend to be heavily linked to the instructional style to make them believable in terms of eliciting ethical decision-making from business dilemmas.

Textbooks are perceived by learners as academic material, hence a challenge in utilization to derive vignettes for developing ethical ideology. This is attributed to the fact that textbooks contain things that learners are used to and have certain expectations about. Through a systematic piecemeal extraction of information to make vignettes, textbooks provide an orderly way in aiding learning. Generally, textbooks serve as a guide to business ethics phenomenon by providing a general outline of the concept of intended content with no personal attachment to business dilemmas. However, textbooks are helpful in reinforcing learners' desires to be ethically sensitive in making decisions through presentation of information in relatively straightforward approach. It is encouraging to business education learners to develop an ethical ideology to 
articulate core personal values through vignettes derived from textbooks. This is because of systematic flow of information that would guide thought process and decision-making. Compared to traditional lectures, experiential learning using vignettes derived from textbooks enable learner gain knowledge on business ethical issues, which could be applied in a real-life situation. Irrespective of being abstract textbooks would influence ethical decision-making among business ethics learners through emphasis, diversity, and integration and sequential processes in aiding learning.

Learners' response to any vignette is easily drawn from personal experiences. Therefore, vignettes based on personal experiences easily resonate with learners both in overt and subtle ways. Vignettes from personal experiences provide opportunities for discussions on realistic aspects of business dilemmas. Ideally, personal experiences influence ethical decision making because of seemingly being authentic. Therefore, as a source of content in developing vignettes personal experiences shape ethical sensitivity by providing opportunity for individualized sharing of business experiences. Personal experiences plus accompanying discussion questions enhance moral perception among learners in as far as decision-making is concerned, by creating psychological attachment to business dilemmas. Therefore, personal experiences packaged as vignettes elicit learners' ethical reasoning process resulting in articulation of ideas in a comparative approach during experiential learning. In conclusion, ethical content derived from learners and integrated in training modules enhance effectiveness in teaching business ethics. This is so because vignettes developed from personal experience form a grounded basis for class discussion on ethicaldecision making.

\section{Recommendations}

This study suggests that current educational reform in Kenya should focus on reforms of undergraduate studies to include vignettes among pedagogical approaches in teaching business ethics courses. In practice, adoption of vignettes would promote learner responsibility through facilitating rather than directing learning in class. It will also encourage learners to test out and apply new knowledge through group work and in fostering critical thinking and reflection skills. More research should focus on effectiveness of vignettes in promoting knowledge inquiry among learners.

\section{References}

Akinnuoye M A, Akinnuoye O F, Wan Shuib W A and Mokhtar J (2015): Gender-Based Perception and Appraisal of Geography Education by Students in Malaysian Secondary Schools. IOSR Journal of Research $\mathcal{E}$ Method in Education (IOSR-JRME). Volume 5, Issue 3 Ver. I (May - Jun. 2015).

American Psychological Association (2010) Ethical Principles of Psychologists and Code Of Conduct.

Badua, F., Sharifi, M. \& Mediavilla F.M., (2014). What Makes a Top-Selling Textbook? Comparing Characteristics of AIS Textbooks. Journal of Education for Business, 89 (5), 257-262. DOI: $10.1080 / 08832323.2013 .869531$

Barczyk, Casimer C. and Doris G. Duncan (2012), "Social Networking Media: An Approach for the Teaching of International Business", Journal of Teaching in International Business 23(2), 98-122. DOI: 10.1080/08975930.2012.718703 
Dagar V, Yadav A (2016) Constructivism: A Paradigm for Teaching and Learning. Arts Social Sci J 7:200. doi: 10.4172/2151-6200.1000200

Davis, S., DeZoort, F.T. and Kopp, L.S. (2006). 'The effect of obedience pressure and perceived responsibility on management accountants' creation of budgetary slack'. Behavioral Research in Accounting, 18:1,19-35.

Harland, T., (2014). Learning about case study methodology to research higher education. Higher Education Research and Development, 33 (6), 1113-1122. DOI: $\underline{10.1080 / 07294360.2014 .911253}$

Ismail and Mohd Ghazali (2011): Ethical Ideology and Ethical Judgments of Accounting Practitioners in Malaysia. Gadjah Mada International Journal of Business. Vol. 13, No. 2 (May - August 2011): 107 - 123.https://doi.org/10.22146/gamaijb.5486

Hughes R and Huby M (2002): The application of vignettes in social and nursing research. Journal of Advance Nursing Research. Vol 37. Iss 4 https://doi.org/10.1046/j.1365-2648.2002.02100.x

Kelter J D and Pope A W (2011): The Effect of Child Gender on Teachers' Responses to Oppositional Defiant Disorder. Child \& Family Behavior Therapy, v33 n1 p49-57 2011

Koleva, S., Graham, J., Iyer, Y., Ditto, P.H., \& Haidt, J. (2012) Tracing the threads: How five moral concerns (especially Purity) help explain culture war attitudes. Journal of Research in Personality, 46(2), 184-194 doi:10.1016/j.jrp.2012.01.006

Massoudi M (2010) Learning and Teaching Ethics through Stories: A Few Examples from the Buddhist Tradition Creative Education, 2010, 1, 18-24. DOI:10.4236/ce.2010.11004

Miller, A., Shoptaugh, C. \& Wooldridge, J. (2011). Reasons not to Cheat, AcademicIntegrity Responsibility, sand Frequency of Cheating. The Journal of Experimental Education, 79(2) https://doi.org/10.1080/00220970903567830

Mohd Ghazali A N (2011): The influence of personal attributes and organizational ethics position on accountants' judgments: Malaysian Social Responsibility Journal, Vol. 9 Issue: 2, pp.281-297, https:// doi.org/10.1108/SRJ-08-2011-0072

Oluoch and Odundo (2018): Influence of Vignettes Constructions on Ethical Decision among Business Education Students. World Journal of Educational Research Vol. 5, No. 2, 2018 http://dx.doi.org/10.22158/wjer.v5n2p204

Oluoch P.M., Mwangi J, Odundo P A \& Oyier C R (2018): Effects of Vignettes Types in Enhancing Ethical Decision among Business Education Students. International Journal of Business and Management; Vol. 13, No. 10; 2018 doi:10.5539/ijbm.v13n10p249

Pan Y and Sparks J R (2012) Predictors, consequence, and measurement of ethical judgments: Review and meta-analysis. Journal of Business Research 65 (2012) 84-91. doi:10.1016/j.jbusres.2011.02.002

Qualters D M (2010): Bringing the outside in: Assessing experiential education. Wiley Online Library. Vol 2010 Iss 24. https://doi.org/10.1002/tl.421

Roberts, R., \& Sikes, J. (2011). How IT is managing new demands: Mckinsey Global Survey Results. Mckinsey on Business Technology, 22(Spring), 24-33.

Shafer, W. E., Poon, M., \& Tjosvold, D. (2013). An investigation of ethical climate in a Singaporean accounting firm. Accounting, Auditing \& Accountability Journal, 26(2), 312-343. doi: 10.1108/09513571311303747

Sims R.R. and Sauser W I (2011): Experiences in Teaching Business Ethics. Contemporary Human Resources Journal

Stedham, Y. and Beekun, R.I. 2013. 'Ethical judgment in business: culture and differential perceptions of justice among Italians and Germans'. Business Ethics: European Review, 22:2, 189-201. https://doi.org/10.1111/beer.12018 